\title{
Analysis of building cloud-based smart finance platform of Shanghai
}

\author{
Naijing $\mathrm{Hu}$ \\ School of Information Management \\ Shanghai Finance University \\ Shanghai , China \\ Njhu71@hotmail.com
}

\author{
Yingying Wang \\ School of Information Management \\ Shanghai Finance University \\ Shanghai , China \\ Wangyy@shfc.edu.cn
}

\begin{abstract}
Intelligent Finance is the product that the integration of information technology and modern finance. This paper discusses the conditions in Shanghai which is as a financial centre to support the smart finance, analyze the shortage of financial data and value-added services-based of smart finance, put forward the development of the smart finance based on financial cloud service platform, proposed to design a financial cloud platform with the current situation of Shanghai, in order to promote the modern financial industry business processes, business development, and improve customer service, etc.
\end{abstract}

Keywords- Shanghai financial centre, smart finance, financial cloud, soft power

\section{THE SMART FINANCE}

In January 2009, IBM first put forward "smart planet". The idea of this notion is making full use of IT technology into industries, e.g. "smart finance", "Smart power", "smart medice", "Smart City", "smart transportation", "smart supply chain" and "intelligent" in other areas.

Reform, the only manner to win new competitive advantage, is played an important role nowadays with the opening of financial industry. According to the survey by IBM for more than 1000 CEO during 2006 to 2008, 92\% of the banking CEO recognized the necessity of reform, of which $80 \%$ CEO admitted that banks need to conduct a thorough change.

The attributes of financial industry comes from the digital features of IT technology, whether it is product design, production, sales or the subsequent service. Thus, using information technology to support the smart is a costeffective achievement for financial industry.

IBM believes that the smart finance in the financial business and the technical aspects has of sensor measurements with the three characteristics, more thorough, more comprehensive interoperability and more in-depth insight. It works through the whole instruction, including emerging technologies to achieve more convenient access to comprehend customer information to a keen insight to understand of customers' needs; optimizing and innovating the service efficiency and customer service; and, design dynamic business support system(s) to respond to business changes flexibly for achieving business value innovation through risk control management.

IBM believes that the smart finance should focus on four areas, the innovation and transformation, the implementation of integrated risk management, the enhancement of cuttingedge insight and resilience, and dynamic infrastructure.

- Innovation and transformation: provide personalized financial products and services all the time through the perception patterns of customer behaviour.

- Integrated risk management: predict and avoid all kinds of financial risks for the financial industry using quantitative techniques.

- Cutting-edge insight and adaptability: improve the ability of intelligent analysis for responding to subtle changes in huge amounts of data.

- Deployment of IT infrastructure: a dynamic IT infrastructure through timely response to the needs of financial services.

II. The hard environment and advantages of Shanghai financial intelligence

In March 2009, State Council first formed that to construct Shanghai as an international financial centre in China which focus on strengthening Shanghai's financial market system. After years of development, Shanghai's financial industry has historically achieved the goals that complete the business system construction, data centralization and other e-finance the construction. In the next 10 years to 15 years, Shanghai will gradually focus on financial services and financial management.

Based on the Lujiazui Finance and Trade Zone, Shanghai has formed the basis of the smart financial development infrastructure of financial information service industry. It also has good financial support for the development of smart hard environment.

\section{A. The leading environment}

- Financial institutions: Shanghai has gathered 850 Chinese-funded and overseas financial institutions in total, of which more than 100 are overseas institutions.

- Market construction: Shanghai has various financial markets, e.g. foreign exchange, gold, interest rates, interbank lending and derivatives etc.

- Infrastructure: The infrastructures of Lujiazui area are about the same as it of Manhattan in New York, Ginza in Tokyo.

\section{B. The financial data centre}

Shanghai is a large-scale financial data centre. As the financial information service industry base, Shanghai has 
nearly 30 data centres which including the People's Bank, Citibank, China Ping An Bank, China Bank, Shanghai Bank, Fujian Industrial Bank and other financial institutions. The securities industry in Shanghai is also formed a separate data centre for selling data; in addition, the insurance industry is also building their own data centres.

\section{The well-developed smart finance sector}

Shanghai's currently has eight software bases which provide financial products. Lujiazui area, for example, 58 IT enterprises are engaged in software development which 14 of them covers financial securities, financial information, data analysis, financial services outsourcing, financial services and intelligent industry. United Financial, CCID capital exercise, Wind, Shanghai Securities Information Co., Ltd. and other financial information consulting firms occupy a certain market share; Xinhua 08 which settled in Shanghai in 2009, further promote the the smart the financial industry; In addition, many small consulting organizations continue to emerge and enrich the smart the financial industry in Shanghai.

\section{The limitation of Shanghai smart finance development}

\section{A. Based on the value-added data intelligence}

With the rapid development in the information society, all kinds of complex service systems, financial innovation, financial risk management are the features of the wisdom while data processing is the crucial part of its intelligence performance. Table 1 compared it with to traditional hardware-software development.

\begin{tabular}{|c|c|c|c|}
\hline Properties & hardware & software & Data \\
\hline $\begin{array}{c}\text { Standardizati } \\
\text { on degree }\end{array}$ & High & medium & low \\
\hline Price trend & decrease & $\begin{array}{c}\text { Remain } \\
\text { unchanged }\end{array}$ & Increase \\
\hline $\begin{array}{c}\text { Time of } \\
\text { Large-scale } \\
\text { development }\end{array}$ & 1980s-1990s & 1990 s-2000s & $2000 \mathrm{~s}$ \\
\hline $\begin{array}{c}\text { World } \\
\text { Expenditure } \\
\text { of 2010 }\end{array}$ & 3317billion\$ & $\begin{array}{c}2315 \\
\text { billion\$ }\end{array}$ & $\begin{array}{c}8243 \\
\text { billion\$ (I } \\
\text { T } \\
\text { Services })\end{array}$ \\
\hline
\end{tabular}

Table 1 The comparisons of hardware, software, data

\section{B. The limitation of soft environment}

However, due to the constraints in terms of historical, institutional, practical limitation, the development of Shanghai's financial industry's products and services is far behind the West's financial industry. At the point of input distribution, investment in the domestic financial industry: hardware accounted for 57 0.8\%, 24.3\% of the software, services accounted for only $7.9 \%$; the data from overseas' are $30 \%, 30 \%$ and $40 \%$. Therefore, compared to the financial centre as New York or London, the data processing is not broad, not deep enough which may course many problems.

(1) the dispersion of financial data, lack of effective use

One important element of smart finance is collecting and processing huge amounts of data. Although Shanghai is a large-scale financial data centre, but data sharing is not currently implemented. All kinds of financial market data and individual data spread across data centres. The government's financial regulation, for example, lack of a unified data, will cost the Government in the formulation of monetary policy in the absence of effective data analysis, thus, it cannot support the "smart" government.

(2) The lack of financial products and business valueadded services

Smart finance help business decisions making through intelligent analysis of data. Aimed with data mining, data model and mass treatment of advanced technology, using financial data and intelligent analysis, smart can strength customer satisfaction and achieve timely, effective, intelligent decision support.

However, the shanghai smart market share is not impressive. In 2009, China's financial data market spending only \$ 3.42 billion among \$ 226.8 billion of global market. In China's financial data market, the total coverage of WanDa, Great Smart, QianLong, TianXiang Investment Information, Shihua, Wan Guo, the Asian Economic Data, North Star, HeXun, Xinhua 08 and other financial Data is less than a Reuters company; the Chinese products still stand at original data-based whilst macro-data analysis, complex data analysis has not really start . In general, they are scattered, repeat, "small"," raw materials" and lack of follow-up of financial data processing and value-added services.

\section{The cloud platform of smart finance}

Cloud computing is the product of computer technology and the fusion of business operations through information technology. Cloud computing architecture of smart finance and customer service centre has a very good meeting point, in order to build a cloud computing platform for financial services.

A.

\section{The financial cloud computing}

\section{(1) cloud computing}

Cloud computing is a model of business computing. It refers to usage patterns of the delivery of IT infrastructure, distributed computing tasks onto a large number of computers through the network to obtain the necessary resources (hardware, platform, software). There are three models of services, SaaS (Software as a Service), PaaS (Platform as a Service) and laaS (Infrastructure as a Service), thus, software as a service, platform as a service, infrastructure as a service to users.

(2) The financial cloud platform 
Cloud computing can effectively achieve the integration of resources, aggregation, virtualization and automation, to achieve full sharing of information. The financial data centre, based on the use of cloud computing architecture integrates the disparate financial data centre. Taking advantages of cloud services technology, the proliferation of service capabilities with the construction of the financial products portfolio can constitute value-added services; substantially increase the ability of processing financial data. It can enhance the ability of the intellectual and financial.

\section{B. the cloud platform of smart finance can promote the development of financial environment}

(1) data integration

Through the formation of Shanghai data centre building financial data sharing standards, integration of variety of data, the cloud platform can service shanghai and the Yangtze River Delta.

On the one hand, the cloud platform can provide an accurate, sensitive, and extended financial system. It helps shanghai has the ability of measuring, modelling, processing, analysis of a large number of structured and unstructured financial data which is the ability to form the basis for the smart finance.

On the other hand, it can service for government, financial institutions, colleges and universities in order to increase the ability of financial decision-making, financial market regulation and financial product innovation. It can enhance the small financial consult institutions, financial intermediaries and other financial industry.

(2) enhance the value-added services

Based on data analysis and processing, cloud platform can provide financial services products, e.g. external provision of financial data analysis, the risk of financial assets management, derivatives pricing, trading automatic trading strategy simulation and model validation assessments and other financial cloud services.

One hand, it can work for government in terms of providing a wealth of smart, financial services by policy analysis tool. It focuses on a variety of market information and achieves the regulatory channels of public funds by screening, analyzing, and prediction of macro-trends.

The other hand, it provides services to the market that on income and credit derivatives pricing, stock, option pricing, risk measurement and other services that can enable small enterprises avoid to repeat the financial system and applications.

\section{V. the development of Shanghai's financial cloud- platform}

The development of Shanghai's financial cloud-platform can take advantages from building financial institutions, which can significantly improve the ease of access to financial data, reduce the cost of financial data processing.

\section{A. financial analysis of the cloud platform build}

Shanghai has cloud-based environment, including cloud computing in terms of data hardware environment soft environment.

(1) the hardware of cloud computing

Shanghai Super Computing Centre is one of the main project of Shanghai Harbor, with powerful hardware support for high-performance computing, including computing resources and the Dawning 4000A Dawning 5000A (Cube) supercomputer. Dawning 4000A has 2128 2.4GH CPU, the peak computing speed of 10.2 TFlops. It was ranked the world's tenth in 2004; Dawning 5000A supercomputer with 6400 quad-core processors, floating point peak was 230TFlops, 2009 was ranked the world's tenth. They are now work for the weather forecasting, drug design, life sciences, automotive, new materials, aviation, aerospace, marine and other applications provide a large number of high-performance computing applications.

(2) Data soft environment

Shanghai has nearly 30 financial institutions, also has a Wind China Financial Database, sharp financial research database (RESSET), National Taian CSMAR (China Stock Market \& Accounting Research Database) series database, CCER China's economic and financial databases, and many other international economic databases. Data can be covered as the capital, currency and other microeconomic and macroeconomic fields. The combined data can work for predicting the global financial crisis, financial strategy development, small financial product design / analysis of exchange rates / market analysis.

\section{B. the architecture of financial cloud platform}

Financial cloud platform includes the super calculation servers and shanghai financial data. Based on this platform, financial decision, financial models like financial decision, market supervision and financial product innovation will produce value-added services. Figure 1 shows the Financial cloud-platform Architecture

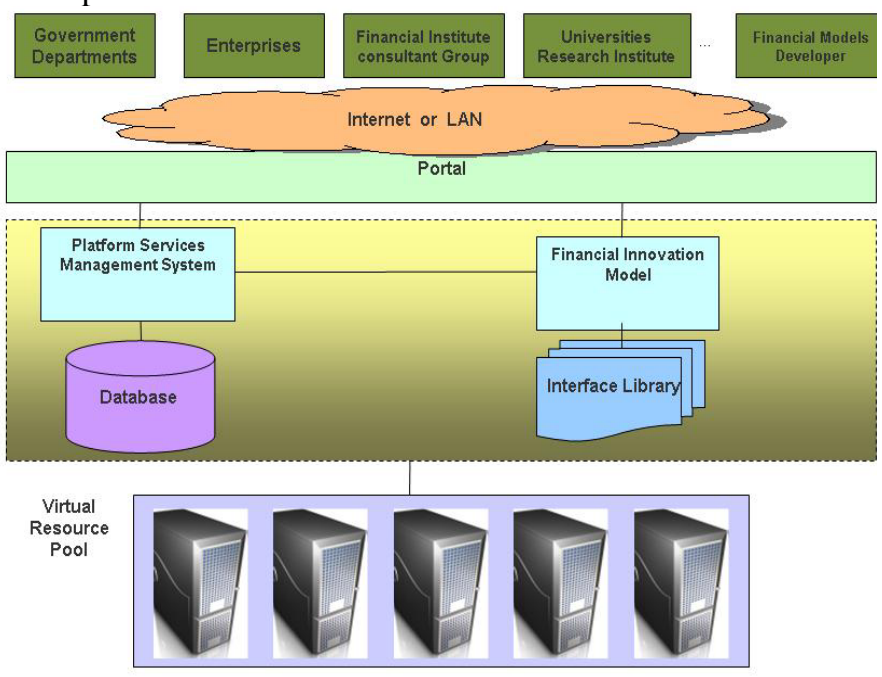

Figure1: Financial cloud-platform Architecture 
- Virtual resource pool: cloud computing resources provide flexible configuration of data that scheduling for data pre-processing, data query, and financial computing simulation.

- Database: integration data from various data centre, used to support financial decision making, financial services, financial innovation model calculations.

- Platform of service management: resource management, including, function modules, user management, etc. to achieve the daily management of the financial cloud.

- Financial innovation model: the realization of the company's financial analysis, e.g. financial investment decisions, financial native product pricing (currency, stocks, credit, bonds and physical commodities, etc.), pricing of financial derivatives (forward, futures, options, swaps), risk measurement, assessment and management functional model components.

- Interface library: the programming environment, including $\mathrm{C} / \mathrm{C}++$, C \#, FORTRAN, Java, Python, R, Excel VBA, Matlab, SPSS, SAS and other basic financial computing languages and software, and OPENMP, MPI, MapReduce and other parallel computing environments, various types of financial products to support application development.

\section{C. $\quad$ services of financial cloud platform}

The services of financial cloud platform implement the transparent managements and schedules of the low level hardware, system level software and middle level data. It provides the flexible services of financial models according different data demanding. The services of financial cloud platform include:

- Provide the tools of economic policy analysis for the government in order to realize the multi-warning and early-warning models to avoid financial risk .across the regions and the fields.

- Provide financial and business decision analysis tools to enable enterprises to access to financial services and save a lot of construction and operation and management costs.

- $\quad$ Provide the pricing models for financial, advisory bodies and credit derivatives.

- Provide a research platform for faculty of universities, research institutes and other organizations.

\section{Conclusion}

As the financial centre, Shanghai has massive amounts of data. Financial cloud can improve the ability of the intelligent analysis and support the financial decision capabilities. It is the next development direction of the financial industry in Shanghai. By building a financial cloud private cloud, personal service can be promoted sharply. However, the financial cloud has also brought many challenges, especially information security issues, such as information resources, and data calculation, storage and delivery, etc. With those issues properly solved in the future, the smart finance of cloud-based Finance will promote the transformation of the financial industry and innovation, and effectively enhance the soft power of Shanghai.

\section{REFERENCES}

[1] Zhou huan, Li Guangming, Hu Naijing, "Introduction of Smart financial Forum”, Journal of Shanghai Finance University, 2012-2, pp.118-120.

[2] WU Weihua, "Research on Development Patterns of EC Based on Cloud Computing”, Journal of Intelligence, 2011-05, pp,43-48..

[3] Zhu Yangyong, Hu naijing, "Data Technology:Wisdom Financial Technology Foundation”, Journal of Shanghai Finance University, 2012-2, pp.19-21.

[4] Kevin Yin ," Cloud Computing: Concept, Model, and Key Technologies”, ZTE Communications , 2010-04, pp.33-35.

[5] Wong Jia, Gu Jun, “The Construction and Analysis of Information Resource Aggregate in the Social Informatization Measurement System” , Library and Information Service;, 008-03, 56-59.

[6] LI Yong-xian, ,LUAN Xu-lun,, LI Sen-sen,” On the Application of Cloud Computing Technology in Library" , The Journal of the Library Science in Jiangxi, 2009-01,pp.67-71. 